\title{
Transforming mathematics classroom practice through participatory action research
}

\author{
Pete Wright ${ }^{1}$ \\ Published online: 16 January 2020 \\ (c) The Author(s) 2020
}

\begin{abstract}
This paper explores the potential of participatory action research to bring about significant changes in practice in a context in which more conventional approaches to research have had limited impact. It focuses on secondary mathematics classrooms where teaching approaches characterised by memorising and practising mathematical procedures, with little understanding of their application, purpose or underlying concepts, remain commonplace in many countries around the world and have proved highly resistant to change. The paper highlights the damage caused by such practices in terms of the alienation of large numbers of students and the inequitable outcomes they are associated with, including the strong correlation that persists between students' socio-economic status and mathematical attainment. It reports on the case of one participatory action research project, involving the author and five teacher researchers, that demonstrated how a vision of mathematics education, involving a genuinely engaging and empowering curriculum, can be translated into classroom practice. The paper considers the extent to which this research project was conducted in a collaborative, systematic and rigorous way. It reflects on the research processes that facilitated critical reflection, enabled the teacher researchers to overcome constraints and generated trustworthy findings. The insights gained from this analysis are used to argue that a participatory action research methodology, which resonates with a critical mathematics pedagogy, has the potential to challenge prevailing discourses in mathematics education and hence lead to genuine transformations in classroom practice.
\end{abstract}

Keywords Critical mathematics education · Equity $\cdot$ Social justice $\cdot$ Empowerment · Participatory action research

\section{Introduction}

Mathematics education in England has received a great deal of attention from policy-makers over the past 35 years, with numerous government-commissioned reviews of practice (e.g. Cockcroft 1982; Smith 2004; Vorderman 2011). However, despite large-scale government-initiated curriculum reforms and professional development programmes, including

Pete Wright

pete.wright@ucl.ac.uk

1 UCL Institute of Education, London, UK 
the introduction of functional skills (QCA 2007) and the National Strategy (DFEE 2001), and seemingly endless reforms of the National Curriculum (Oates 2010), school mathematics appears to have changed very little (Morgan 2010). Conventional teaching approaches persist, particularly in secondary schools (years 7-11), regardless of calls from the mathematics education community for a more engaging curriculum with greater emphasis on reasoning skills and the development of conceptual understanding (ACME 2011; NCETM 2008; OFSTED 2012).

In this paper, I argue that change is desperately needed in the way that mathematics is commonly taught to avoid successive generations of learners becoming alienated from the subject. I also draw attention to how school mathematics in its present form produces high levels of inequity, with a persistent and strong association between learners' attainment and socio-economic status. I consider why conventional approaches to mathematics education research have failed to close the gaps in mathematical attainment between different socioeconomic groups or bring about significant changes in classroom practice. I highlight the tendency of research to ignore the sociocultural aspects of mathematics education and the constraints and challenges faced by teachers in the mathematics classroom. Teachers are too often relegated to passive consumers of research, encouraged to implement its findings without understanding how these were generated or participating in research themselves.

Brydon-Miller and Maguire (2009) argue that participatory action research (PAR) involves collaborating with marginalised and oppressed communities and addressing the underlying causes of inequality. And yet PAR, which involves collaboration between teachers (many of whom routinely work with students from marginalised communities) and academics, and taking account of the sociopolitical forces that contribute towards maintaining the status quo, remains under-exploited as a research methodology in the field of mathematics education. Most teachers and learners of mathematics that I have come across appear to be unaware of the exploitation and social inequities that exist, and are perpetuated by school mathematics. I explore in the later sections of this paper the potential of PAR for exposing and challenging these inequities. I draw on my experiences of conducting the Teaching Mathematics for Social Justice (TMSJ) research project, a collaboration between myself and five teacher researchers, which adopted a critical model of PAR (Skovsmose and Borba 2004).

The findings of the TMSJ project highlight how the participatory and collaborative nature of the research design facilitated teachers' critical reflection on existing practice. It enabled teacher researchers to overcome constraints they faced in transforming their own classroom practice and develop teaching approaches which enhanced the engagement and agency of students (Wright 2016, 2017). By considering the characteristics of, and the research processes employed in, the TMSJ project, I argue that PAR has the potential to bring about transformations in classroom practice in a context in which more conventional approaches to research have had limited impact and in which change is desperately needed.

\section{Disengagement and inequity in school mathematics}

I draw attention below to high levels of disengagement amongst learners, and inequitable outcomes in terms of attainment and participation, which serve as a strong justification for why change is desperately needed in mathematics classrooms. The majority of students continue to experience an uninspiring mathematics curriculum in which learning is limited to memorising and practising mathematical procedures, with little understanding of 
their application, purpose or underlying concepts (Foster 2013, OFSTED 2012), resulting in the quiet disaffection of a large proportion of students (Nardi and Steward 2003). The aspirations for mathematics education articulated in the latest National Curriculum, i.e. to provide "a foundation for understanding the world, the ability to reason mathematically, an appreciation of the beauty and power of mathematics, and a sense of enjoyment and curiosity about the subject" (DFE 2013, p. 2), seem far from being realised. Williams and Choudhury (2016) report how transmissionist pedagogies (characterised by teachercentred approaches) were found to accelerate a general decline in students' dispositions towards studying mathematics over the course of their schooling and were a significant factor in students opting out of further study. Negative experiences of mathematics are not limited to students in England. Skovsmose (2011) highlights the dominance worldwide of an exercise paradigm in which teachers demonstrate a mathematical procedure to students who then complete a series of almost identical closed questions. As a result, large numbers of children and adults exhibit anxiety towards, and alienation from mathematics, which is commonly perceived by the general public as "dull, irrelevant, useless and often harmful" (Grootenboer 2013, p. 324).

Prominent mathematics education researchers (e.g. Boaler 2009; Skemp 1972; Swan 2006) have called repeatedly for the adoption of alternative pedagogical approaches that promote problem-solving, discussion and collaborative learning. Most tutors that I have come across in initial teacher education (ITE) over the past 8 years (since becoming a teacher educator), in common with those who helped me qualify as a teacher in 1987, routinely encourage their student teachers to engage with such pedagogies and related research findings. Yet these practices still remain far too uncommon in mathematics classrooms.

Several researchers have drawn attention to the persistent and strong correlation between students' socio-economic backgrounds and their participation and attainment in school mathematics, which has existed in many Western countries for over 40 years (Boaler et al. 2011; Jorgensen 2016; Noyes 2009). Whilst differences in achievement between other groups (e.g. boys and girls) have narrowed over the same period, social class remains the most decisive factor in determining success in school mathematics (Ernest 2016; Jorgensen 2016), which in turn regulates access to higher-status university courses and better-paid employment (Black et al. 2009). Thus, mathematics education "still serves as a powerful fractional distillation device that separates off different sectors of the population for different rewards" (Ernest 2016, p. 119). Jorgensen et al. (2014) highlight how some social and cultural resources are assigned greater value and recognition by schools. These resources include the language and behaviours that tend to be acquired by children from middleclass families as a result of their upbringing, which enable them to make better use of the opportunities provided by schools from the moment they arrive (Noyes 2008). As a consequence, they are more likely to have positive learning experiences, identify themselves as mathematics learners and choose to study the subject beyond compulsory level (Williams and Choudhury 2016). In contrast, working-class children are more likely to have negative experiences of learning, see themselves as failures and disengage from mathematics (Jorgensen 2016).

So what can teachers concerned with equity and social justice do within such a structurally inequitable school system? Jorgensen (2016) argues that such teachers should strive to help working-class students adopt the middle-class values and behaviours recognised by the school, for example by demonstrating the relevance and application of mathematics to solving real-life problems in order to enhance their motivation and mathematical engagement. She acknowledges that, in doing so, care must be taken to avoid providing an impoverished and purely functional curriculum that fails to provide opportunities to appreciate 
the beauty of mathematics or the work of real mathematicians. She highlights examples of good practice where schools have raised the mathematical attainment and confidence of disadvantaged students, whilst at the same time providing a rich and stimulating learning environment. One such example is the Railside Project in a deprived area in California (USA) that successfully adopted a collaborative, problem-solving approach to teaching mathematics, resulting in higher attainment and more positive attitudes towards mathematics amongst students than in comparable schools (Boaler 2008).

Williams and Choudhury (2016) argue that critical mathematics pedagogy should confront transmissionist pedagogies, focussed primarily on preparing students for tests, and promote those that have greater use value, e.g. in modelling and solving real-life problems. However, Norton (2017) highlights the danger of focusing exclusively on knowledge that is immediately relevant to everyday life in an attempt to make the curriculum more authentic and engaging. This might increase students' intrinsic motivation in the short term but prove counterproductive in the longer term by denying them access to powerful knowledge. Straehler-Pohl and Gellert (2013) describe mathematics classes in a low-streaming school in a deprived area of Berlin, in which students were routinely provided with closed tasks restricted to repeating techniques. Whilst the tasks were mainly abstract and decontextualised, they did not involve legitimising the use of techniques, thus restricting disadvantaged students' access to powerful knowledge. Barrett (2017) stresses the vital role teachers must play in ensuring that "the relation between academic and non-academic discourse is articulated such that the possibility for the development of new meanings and understandings is realized among students" (p. 8).

Critical mathematics educators, such as Skovsmose (2011), argue that school mathematics should go beyond providing learners with the reasoning and skills they need to solve problems encountered in real life. It must also empower students to become active citizens, to lead satisfying and fulfilling lives and to contribute towards tackling some of the pressing issues currently facing society, such as growing inequality, human rights abuses and environmental sustainability (Cotton 2013). A truly empowering curriculum should enable learners to use mathematics to investigate and challenge injustices they experience in their own lives and wider society (Gutstein 2006), and involve opening up the mathematical modelling of real-life situations to scrutiny and revealing their often-invisible ethical dimensions (Yasukawa et al. 2016).

The problems highlighted above justify why change is desperately needed in school mathematics. I turn my attention now to consider why, despite consistent calls amongst the mathematics education research community for a more engaging and equitable school mathematics curriculum, there has been little change in practice in mathematics classrooms.

\section{The implications for mathematics education research}

There is an abundance of published research focusing on equity and social justice in mathematics education, including several edited books and special issues of journals devoted to these issues (e.g. D’Ambrosio et al. 2013; Gates and Jorgensen 2009; Strutchens et al. 2012). Yet school mathematics continues to play a significant role in perpetuating social inequity by alienating large numbers of students and disproportionately restricting access to higher education and better-paid jobs for disadvantaged learners. So why has mathematics education research had such limited success in challenging this situation? I argue in this 
section that a significant factor is the failure of most conventional research to take adequate account of the sociopolitical nature of school mathematics and the challenges and constraints facing teachers in the classroom.

Critical mathematics education challenges the myth that mathematics can be considered to be neutral and argues that agency, empowerment, critical understanding and sociopolitical engagement should all be key features of teaching and learning mathematics (Ernest and Sriraman 2016). It offers an alternative explanation for why conventional mathematics teaching has proved so resistant to change, regarding existing practice as indicative of the interests of those in positions of power (with privileged influence over policy decisions) in maintaining the subservience and exploitation of certain groups within society. Skovsmose (2011, p. 9) argues that the exercise paradigm (see the previous section) helps prepare young people for "participating in work processes where a careful following of step by step instructions without any question is essential". Gutstein (2006, p. 10) contends that the current disempowering mathematics curriculum experienced by many reflects the economy's need for "an ever-growing army of low-skilled, compliant, docile, pleasant, obedient service workers". Critical mathematics education contends that research is sociopolitical in nature and claims by other researchers to objectivity and a lack of bias are merely denying the power relationships and ideologies that permeate the field (Valero 2004). Jorgensen (2016) argues that most mathematics education research fails to recognise social class as an issue which undermines its potential to enable all learners to enjoy the personal and economical rewards that success can bring. Williams and Choudhury (2016) warn against relying too much on studies that focus exclusively on effectiveness whilst ignoring the affective domain. They highlight how focusing on raising attainment in the short term can adversely affect dispositions towards learning mathematics, achievement and participation in the longer term.

Francis et al. (2017) highlight how the little research that does exist, which addresses the sociopolitical nature of mathematics education, is often ignored by policy-makers. They consider the high-profile case relating to ability grouping. They describe how the practice of setting students, by grouping together those with similar levels of prior attainment in homogenous teaching groups, has grown significantly in recent years, with $71 \%$ of secondary students in England set in mathematics. This is despite most research evidence suggesting that setting has no significant benefits on overall levels of attainment and a negative impact on outcomes for students in lower sets. Students are often assigned to sets on the basis of their behaviour, rather than their attainment, with limited opportunities for subsequent movement between groups (Wilkinson and Penney 2014). Those placed in lower sets commonly experience a "largely remedial (and boring) curriculum" (Hodgen and Marks 2009, p. 31). Students from poorer backgrounds are invariably overrepresented in lower sets, where they are less likely to be taught by well-qualified teachers or to experience deep learning focused on conceptual understanding, thus further consolidating their disadvantage (Jorgensen 2016).

Francis et al. (2017) attribute the lack of impact of this research to a dominant discourse, i.e. a way of constituting knowledge that comes to be viewed by society as representing the "natural order [which] needs no external evidence to support it" (p. 9). In this case, the dominant discourse views inequalities in outcomes as an inevitable consequence of innate differences in ability, and segregation is seen as a natural way of dealing with these differences. They argue that this discourse arises from "long-standing narratives in English culture" (p. 8) associated historically with a school system in which (selective) grammar schools and (fee-paying) independent schools exist alongside government-maintained comprehensive schools. This explains why schools often feel compelled to introduce setting to 
attract middle-class parents, seen as keen to secure advantages for their own children, in order to boost examination results.

Given the need to challenge such deeply rooted discourses, mathematics education research must pay careful attention to teachers' perspectives, their classroom situations and the constraints they face (Bishop 1998). Much conventional research, however, is conducted in prototypical classroom situations which lack the typical challenges encountered by most teachers on a daily basis (Skovsmose 2011). Findings from such studies are often packaged and disseminated to schools for implementation. However, since they ignore institutional contexts and constraints, they have minimal success in challenging existing classroom practice. The blame for the continued lack of evidence-informed practice is then either placed on teachers for being reluctant to engage with the research (Oakley 2006; Sebba 2004) or on the poor quality of the research itself (Gough 2004). Watson et al. (2013) argue that, despite an abundance of research into effective learning of mathematics, this research is not made readily accessible to teachers. Sebba (2004) contends that teachers have such deeply entrenched beliefs and values relating to learning mathematics that they resist all attempts to transform their practice; hence, change is only possible through adopting more effective ways of managing policy implementation and imposing tighter control on teachers.

Whilst a minority of teachers are involved in carrying out research, the majority are expected to implement, unquestioningly, recommendations for changes in practice arising from (carefully selected) research which they know very little about. These expectations are often presented as targets associated with performance management procedures in schools, resulting in teachers distrusting new research findings, seen as promoting a political agenda or as tacit monitoring (Hammersley 2004; Thomas 2004). Given the need for research which challenges current orthodoxies, teachers need to develop their capacity to reflect critically on existing practice in relation to research evidence, rather than relying on adopting what works protocols (Winch et al. 2013). Cordingley (2013) argues that, by engaging in collaborative enquiry facilitated by external experts, teachers are encouraged to take risks and explore why, and in which contexts, certain practices are effective. Leat et al. (2014) distinguish between engaging with research, as a body of knowledge, and engaging in research, as a social practice. They argue that teachers who engage successfully both in and with research are more likely to generate new insights and perspectives, affect powerful changes in their practice and become more critical of existing policies and practice.

\section{Collaborative research involving teachers and researchers}

There has been a resurgence of interest recently in close-to-practice research involving teachers and researchers working together to address problems in practice. It is widely acknowledged that such research, due to significant involvement of teachers, has the potential to impact on professional learning and to challenge established practice (Myhill 2015). However, the biggest challenge facing close-to-practice research is the common perception that it lacks rigour and is limited in scale, prompting BERA (2017) to commission a review into its quality. Robutti et al. (2016) report that most practitioner-led collaborative research neglects to theorise collaboration and relies instead on theories relating to a community in which it is assumed to take place. One collaborative research methodology that has recently proliferated worldwide is lesson study, its popularity attributable to its widespread 
use over many years for professional development of teachers in high-performing jurisdictions in East Asia (Takahashi and McDougal 2016). Lesson study models incorporate characteristics that can facilitate effective professional learning, i.e. "it is sustained over substantial periods of time, collaborative within mathematics departments/teams, informed by outside expertise, evidence-based, research-informed, and attentive to the development of the mathematics" (Wake et al. 2016, p. 245). However, these models appear to have developed organically, through the collaborative practice of teachers, and only recently become a focus for study by academic researchers (Takahashi and McDougal 2016).

Unfortunately, much collaborative research fails to recognise the sociopolitical nature of school mathematics and lacks the critical element necessary for challenging existing practices and dominant discourses. Lesson study normally involves advance agreement of the intended outcomes which is used to determine the research questions. Japanese lesson study, for example, is associated with the implementation of a specific problem-solving pedagogy around which there is already shared consensus amongst mathematics educators (Takahashi and McDougal 2016). Whilst action research is not uncommon in schools, much of it is either technical, i.e. it aims to improve practice by achieving pre-defined outcomes, or practical, i.e. the focus is left open for practitioners to decide but the legitimacy of existing modes of practice is not questioned (Kemmis 2009). Critical reflection requires that teachers view their own practice as problematic and question the consequences of their actions in relation to wider historical, cultural and political values and beliefs (Hatton and Smith 1995; Liu 2015). External stimulus is regarded as essential for promoting critical reflection in schools since, without this, collaborative enquiry is likely to merely perpetuate existing practice through the process of alignment with accepted norms (Jaworski 2006). Action research only becomes critical when it involves partners working together to "change their social world collectively, by thinking about it differently, acting differently, and relating to one another differently" (Kemmis 2009, p. 471).

In the next section, I propose that participatory action research (PAR) offers the potential to bring about changes in practice where more conventional research has failed to do so. I argue that PAR presupposes a genuine partnership between teachers and researchers, recognises the sociopolitical nature of research and can be conducted in a rigorous and systematic way that promotes critical reflection on existing practice and facilitates transformations in classroom practice.

\section{Participatory action research}

Participatory action research (PAR) is a collaborative approach to research in which researchers aim to carry out research with practitioners (as research partners) rather than on practitioners (as research objects). In the context of schooling, it recognises how academic researchers, with their expertise in conducting research, and teacher researchers, with their in-depth knowledge of the classroom situation, each have a distinct, but essential, role to play (Atweh 2004). It aims to seek positive social change through generating knowledge that is of greater relevance to practitioners, whilst developing a deeper understanding of theory-in-practice amongst teachers (Brydon-Miller et al. 2003). It pays closer attention to teachers' perspectives, the challenges and constraints they face and the opportunities they are afforded on a day-to-day basis. PAR is overtly emancipatory and rejects the notion that research can be objective and value-free, which distinguishes it from other forms of action research. Brydon-Miller and Maguire (2009, p. 80) describe PAR as “... 
a systematic approach to personal, organizational, and structural transformation, and an intentionally and transparently political endeavour that places human self-determination, the development of critical consciousness, and positive social change as central goals of social science research".

PAR methods have most commonly been applied to the fields of health (e.g. nursing and health promotion) and technology (e.g. agriculture and environment) and less so to education, where it is usually limited to informal education contexts and adult education (Thiollent 2011). With notable exceptions (including two described below), PAR studies in mathematics education appear rarely in research publications. Raygoza (2016) reports on a project in which she taught mathematics to students, who had recently experienced failure in the subject, in an urban school in Los Angeles (US) with high levels of social deprivation. She describes how her students explored social justice issues around food by conducting a school-wide survey and using the results to generate an argument for change. Her project was participatory in the sense that the students themselves took a lead in conducting the research, whilst developing their own critique of injustices relating to their situations. Andersson and Valero (2016) report on a project in an upper secondary school in Sweden, in which the authors (teacher and researcher, respectively) challenged traditional pedagogies and attitudes towards mathematics through the introduction of classroom projects involving societal issues. They demonstrated how changes in pedagogical discourses are possible on a school-wide basis. Both of these PAR studies were limited in scale, with the former restricted to a collaboration between teacher and students within one class and the latter located within a single school. Andersson and Valero (2016) adopted the critical research model of PAR, which is the same model that I chose to adopt for the TMSJ project and is described below.

Skovsmose and Borba (2004) offer a critical research model of PAR, resonating with critical mathematics education, built on the premise that the existing situation must be challenged by addressing "possibilities that can be imagined and alternatives that can be realised" (p. 214). They theorise how this might be accomplished through three key processes (Fig. 1) that are integral to their research design. Pedagogical imagination (PI) is the process of developing a critical understanding of the current situation (CS) and articulating an alternative vision, i.e. imagined situation (IS), by drawing on previous research findings, theories and teachers' practical knowledge. Practical organisation (PO) involves cooperation between teachers, researchers, students and others in organising an arranged situation (AS), i.e. trying out ideas from the imagined situation, taking into account the realities and constraints of the current situation. Explorative reasoning (ER) involves analysing the outcomes from the arranged situation in order to better understand the current situation and to draw conclusions about the feasibility of the imagined situation.

This critical research model, through making explicit the key research processes, offers a systematic form of PAR that has the potential to challenge existing practice and prevailing discourses in mathematics education through its focus on the critical reflection of

Fig. 1 Model of critical research (Skovsmose and Borba (2004, p. 216)

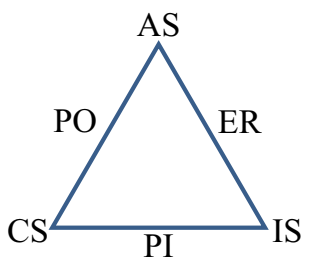


teachers. I report below on how the model was developed and applied in the design of the TMSJ project that aimed to develop alternative teaching approaches that engage and empower all learners.

\section{The Teaching Mathematics for Social Justice (TMSJ) research project}

I report below on the case of one participatory action research project, which demonstrates the potential of the methodological approach for bringing about transformations in classroom practice. In June 2013, as part of my doctoral studies, I established a research group together with five teacher researchers, Anna, Brian, George, Rebecca and Sarah (all pseudonyms). All five had previously completed an ITE programme (on which I was a tutor), were nearing the end of their first year as newly qualified secondary mathematics teachers and had expressed an interest in addressing issues of social justice in their classrooms. They all taught in multi-ethnic comprehensive schools in London, which shared many characteristics including having relatively high proportions of students who were eligible for free school meals, who spoke English as an additional language and who had statements of special educational needs.

Whilst there is an abundance of research literature around social justice in mathematics education, most of this is theoretical in nature and there are relatively few studies that focus on how social justice can be realised in the classroom (Duncan-Andrade and Morrell 2008; Wright 2015). The project therefore focused on the following research question: How can a commitment towards "education for social justice" amongst mathematics teachers be translated into pedagogy and classroom practices which promote such aims? A second aim of the research project was to explore the potential of a participatory action research (PAR) methodology for achieving this.

The research design was based upon Skovsmose and Borba's (2004) critical research model (see the previous section) and was collaborative and participatory in nature. The current situation in this case was represented by conventional teaching approaches and dominant discourses in mathematics education. The imagined situation was based on the following conceptualisation of teaching mathematics for social justice (Wright 2015, p. 27), which draws on the ideas of critical mathematics educators (see the "Disengagement and inequity in school mathematics" section), particularly Skovsmose (2011) and Gutstein (2006):

- Employ collaborative, discursive, problem-solving and problem-posing pedagogies which promote the engagement of learners with mathematics;

- Recognise and draw upon learners' real-life experiences in order to emphasise the cultural relevance of mathematics;

- Promote mathematical enquiries that enable learners to develop greater understanding of their social, cultural, political and economic situations;

- Facilitate mathematical investigations that develop learners' agency, enabling them to take part in social action and realise their foregrounds;

- Develop a critical understanding of the nature of mathematics and its position and status within education and society (Wright 2015).

The arranged situation involved a series of teaching ideas and activities that the teacher researchers tried out in their classrooms as part of three action research cycles spread over 
the course of one academic year. In order to demonstrate that PAR can be conducted in a systematic and rigorous manner, particular attention was paid in the research design to the three key processes of the critical research model (pedagogical imagination, practical organisation and explorative reasoning) described below. The three key processes were applied in the collaborative spirit of PAR, with teacher researchers' in-depth knowledge of the classroom being drawn upon in developing and trying out ideas, and my research expertise utilised to facilitate discussion around research literature, methods and analysis.

Pedagogical imagination in this case involved developing a critical understanding of existing practice and articulating what teaching mathematics for social justice might look like in the classroom. The first meeting of the research group focused on engaging with critical perspectives. Prior to the meeting, I asked teacher researchers to read the introductory chapter from a book about rethinking school mathematics from a social justice perspective (Gutstein and Peterson 2005). The reading was used to facilitate a discussion on how the ideas related to teacher researchers' own experiences and their viability as alternatives to existing practice. In subsequent meetings, teacher researchers read, and presented for discussion, other relevant publications that I identified from the research literature.

Practical organisation involved cooperation between members of the research group in designing and developing activities and teaching ideas to try out in the classroom. This was the main focus for the second, fourth and sixth meetings of the research group. Teacher researchers were asked to present ideas from existing resources (e.g. Gutstein and Peterson 2005; Wright 2004) and discuss how these might be adapted for use with students, taking into account the constraints of the classroom. The group also discussed how to go about collecting evidence to help evaluate the success of the activities, deciding to employ student surveys as a key tool for doing so. This survey was administered by teacher researchers with their own classes immediately after each activity was tried out. The survey was trialled by teacher researchers during the first cycle, after which the wording was amended and a protocol agreed for how it should be introduced to students in subsequent cycles. The survey aimed to distinguish between students' general dispositions towards learning mathematics and how they felt about the activities tried out through the project. The following two questions were posed: How do you feel about maths in general? What do you think about the maths we did today?

Explorative reasoning involved evaluating and reflecting on the activities tried out in the classroom in order to better understand existing practice and to discuss and develop further ideas. This was the main focus for the third, fifth and seventh meetings of the research group. Teacher researchers took the lead in reflecting on their own teaching, taking it in turn to present their evaluations and to invite questions from other members of the group. They made use of students' feedback from the surveys, along with examples of students' work and notes made in research journals (which were used by the teacher researchers and me to record thoughts and reflections during the project). Presentations were followed by a general discussion to inform the planning of future activities.

\section{Reliability of research findings}

Lincoln and Guba's (2003) framework for ensuring trustworthiness of qualitative research findings was applied to the critical research model in order to further enhance the rigour of its design and the reliability of research findings. I describe below how the four aspects 
of the framework, i.e. credibility, confirmability, transferability and dependability, were adapted to the PAR research design in the case of the TMSJ research project.

Credibility involves ensuring the phenomena being observed are accurately represented. This was addressed through the prolonged engagement of teacher researchers over one academic year, iterative questioning during interviews which followed up on previous responses, reviewing initial findings from data analysis in subsequent research group meetings (similar to member checks in other forms of qualitative research) and comparing responses from student surveys, meetings, interviews and final reports to generate richer meaning (related to triangulating data) (Shenton 2004).

Confirmability means ensuring the findings are derived from the experiences of the researchers rather than any preconceived ideas and beliefs. This was addressed through focusing on reflexivity, e.g. by maintaining research journals. The transferability and dependability of the research, which enable readers of the research to judge the extent to which the findings are relevant to their own situations and to repeat the study if so desired, were established by providing thick descriptions of the context and design of the research (Shenton 2004). Such detailed descriptions, whilst too lengthy to include in this paper, can be found in my doctoral thesis (Wright 2015).

\section{Data collection and analysis}

Data from the research project were generated from audio recordings of meetings and a series of three individual semi-structured interviews, which I conducted with each teacher researcher. I adopted an empathetic approach to interviewing by establishing relationships of trust that enabled stories to be jointly constructed through dialogue (Fontana and Frey 2008). Interview questions were designed to prompt teacher researchers to reflect on the development of their thinking and practice over the course of the project. Hence, the initial and final interviews included such questions as: What does teaching mathematics for social justice mean to you? How do you think social justice relates to your current classroom practice? How do you think your classroom practice has changed, since the beginning of the project, in relation to social justice? Given the focus of the project on exploring the potential of PAR to transform classroom practice, questions were also focused on the plan-teach-evaluate cycles, e.g. Tell me a bit more about the first classroom activity that you tried. How will you approach the second classroom activity? Individually tailored follow-up questions were used to explore responses in greater detail, e.g. How did the classroom activity relate to "teaching mathematics for social justice"? How did the students respond?

At the end of the project, teacher researchers were invited to write a short report on their experiences of participating in the project, and the impact it had on their thinking, classroom practice and their students. The student surveys (see previous section) and the final reports were used as supplementary data. They did not form part of the main data analysis (described below) but were used to compare with its findings to generate richer meaning.

The audio recordings were transcribed and two separate thematic analyses were carried out on the transcripts using meaning condensation and meaning interpretation (Kvale and Brinkmann 2009). The first analysis focused on the development of teacher researchers' thinking and classroom practice, whilst the second focused on the characteristics and processes of the critical research model of PAR. For each analysis, the text was broken down into initial units 
of meaning, based on statements from participants, and the meanings were summarised with descriptive text.

For the first thematic analysis, a category was then assigned to each unit of meaning using inductive coding, whereby the categories are derived from an initial reading of the data. Categories included those relating to views teachers expressed about school mathematics (e.g. "consideration of nature of school maths" and "seeing maths as a legitimate area for issues of social justice") and teachers' perceptions of themselves as professionals (e.g. "reasons for becoming a school teacher" and "interest in personal and professional development"). During the coding process, initial units of meaning were broken down further, so that only one category was assigned to each unit. Each unit was also assigned a property, giving more detail about its meaning, and a score from 1 to 5, giving an indication of the extent to which the unit was seen as affirming that property. To further illustrate this process, I provide an example below from the analysis of an interview transcript.

The following statement (by Rebecca) was identified as a unit of meaning: I think that's what [Brian] was saying wasn't it? It's quite easy to define injustice, than what social justice ... I don't really know what social justice means. The meaning of this unit was summarised as: Easier to define social justice by defining injustice. Little thought given to TMSJ before project. This unit was assigned the code "PreEng T2", "PreEng" representing the category "Previous engagement with teaching mathematics for social justice issues", "T" representing the property "Large amount of thought given", and " 2 " indicating a mostly negative assertion of this property, i.e. Rebecca had given relatively little thought to such issues previously.

The coding was then used to compare commonalities, differences and relationships between units of meaning, by grouping together units with similar codes and re-reading the data (whilst taking account of the context of the discussions in which they were situated), enabling themes to emerge (Gibson and Brown 2009). Such comparisons allowed meaning to be constructed from the teacher researchers' stories, whilst avoiding loss of meaning through simplistic quantifying of codes. Initial findings from the thematic analysis were related back to the underlying theories in order to generate new analytical questions and give further meaning to the data (Jackson and Mazzei 2012). The findings from this analysis, which demonstrate how teachers were able to overcome constraints and transform their classroom practice, are presented in the next section.

The second thematic analysis of the data was carried out using categories derived deductively from the key research processes and characteristics associated with the critical model of PAR (described earlier). The purpose of this analysis was to consider the extent to which the TMSJ project was conducted in a collaborative, systematic and rigorous manner and to inform how the critical model of PAR might be applied to future research that seeks to challenge dominant discourses in mathematics education and transform classroom practice. The findings from this second analysis are presented in the penultimate section. Note that in the next two sections, I have focused on the findings that I consider most relevant to the argument developed in this paper. Further reports of the research findings can be found elsewhere (e.g. Wright 2016, 2017).

\section{Findings of the TMSJ project}

Two themes emerged from the first data analysis which highlight the potential of the PAR methodological approach adopted for the TMSJ project for promoting critical reflection and bringing about changes in classroom practice. 


\section{Theme 1: developing student agency}

All five teacher researchers reported a significant increase in students' engagement with mathematics, associated with the teaching approaches and activities developed through the research project. They witnessed unusually high levels of enjoyment of, and interest in, learning about mathematics and social justice issues when these were tackled in lessons. The feedback from student surveys concurred with these observations:

In general I do not enjoy maths as I think I'm not very good at it. Today I enjoyed the maths lesson as I enjoyed finding out about fair trade and I liked seeing all the statistics of the money different people make from a bar of chocolate. (Rebecca's Year 9 Student, survey response to Fair Trade activity).

Across all classes, a majority of students expressed greater enjoyment of mathematics lessons involving social justice issues. Many students, when asked about mathematics in general, described it as boring and irrelevant. They noticed a difference in the project activities and claimed these helped them to see more clearly applications of mathematics to real life: "I liked what we did today because it was something totally different. We learn more about the world like this, while using maths". (Brian's Year 8 student, survey response to Election activity). Increases in engagement were particularly noticeable amongst low-attaining students and those previously poorly motivated or badly behaved in lessons. One noteworthy example was a Year 8 girl in Anna's bottom set who had previously exhibited such challenging behaviour across all subjects that she was in her last week before being moved to a special school. Despite this, her behaviour during a project on wealth distribution, in which students discussed in groups the fairest way to share out wages between workers in different jobs, was exemplary: "in terms of her enjoyment of the project ... she was asking so many questions, she was putting forward so many views, she was working in a team. She was just like a dream child for the whole project" (Anna, Meeting 3).

The project highlighted the cases of a number of lower-attaining and previously disengaged students who demonstrated the most noticeable increases in motivation towards learning mathematics and positive responses towards the alternative practices adopted by the teacher researchers. However, the limited scale of the project meant that the long-term effect on these students' attainment was not examined and increased engagement does not necessarily translate into higher attainment. As Norton (2017) points out, promoting authentic and engaging curricula, and focusing on everyday knowledge, can instil in students an expectation that mathematics should be fun and immediately relevant to real life, with an associated risk of discouraging them from engaging with more powerful mathematical knowledge. This was reflected in initial concerns amongst some students that, by engaging in social justice issues, they were not doing real mathematics: "It was fun. The presenting was fun and enjoyable. It was okay, but it wasn't really relevant to maths" (Anna's Year 9 student, survey response to Making a Change Project). Barrett (2017) uses the same argument to justify the need to make the links between academic and non-academic discourses clearer to students, the above example indicating that in the early stages of the project these links were not made clear enough. However, higher levels of engagement were accompanied by increasing agency amongst students, suggesting that the risk of focusing exclusively on everyday knowledge was minimised.

Developing students' agency became the main focus for the teacher researchers in the third action research cycle, when they tried the Making a Change project with their 
classes. This project, inspired by Rebecca's experiences of designing a similar activity in the first cycle, involved groups of students choosing an issue of interest to them, using mathematics to develop their understanding of the issue, and presenting an argument for a change they would like to see made. Students particularly welcomed the opportunities to explore links between mathematics and issues of interest to them, and to present their arguments: "They were all so passionate about the things they were presenting about, was the key thing, and the fact that they got to actually tell everyone what they found out" (Anna, Interview 3). Teacher researchers attributed the exceptionally high levels of engagement they witnessed with this activity to the autonomy granted to students in choosing their own issues and making their own decisions about how to research these: "I liked the presentation as I got to do something that I felt strongly about. It gave me a chance to express how I feel, also including maths to support my presentation" (Rebecca's Year 9 student, survey response to Making a Change project). The Making a Change project concluded with students evaluating how effectively they used mathematics to support their argument, exemplifying the legitimisation of mathematical techniques presented by Straehler-Pohl and Gellert (2013) as an essential dimension of powerful knowledge.

The idea of developing mathematical agency originated from Rebecca's engagement with the research literature (Gutstein and Peterson 2005) and appeared to be of growing interest to teacher researchers: "I think the agency thing was definitely something I hadn't considered at the start. Like, I saw it more as applying maths to different situations, rather than using maths to actually change something" (Rebecca, Interview 3). The evaluations of lessons suggest it was also a new way of working (in mathematics) for most students. The success of the project activities in drawing links between social justice issues and mathematics demonstrated how students were able to generate new meaning by relating academic and non-academic discourse (Straehler-Pohl and Gellert 2013): "Today shows us about the unfairness farmers get and how we can help them by using fair trade" (Anna's Year 7 student, survey response to Fair Trade activity). Concurrent increases in students' mathematical engagement and agency over the course of the project demonstrate how students were able to gain an appreciation of the use value of mathematics without being denied access to powerful knowledge.

\section{Theme 2: dominant discourses on ability and attainment}

The teacher researchers recounted how the research project prompted them to reflect critically on their own classroom practice and to recognise dominant discourses within mathematics teaching. All five acknowledged an initial reluctance to try out new ideas and teaching approaches with students in bottom sets through concerns that they would respond negatively:

I know the way that I teach classes that are badly behaved is so structured, to make up for the fact that they can't be left to their own devices for five minutes. ... That kind of approach doesn't really lend itself necessarily to an extended open activity, where they actually get to think more deeply about the things that are involved. (Rebecca, Interview 3)

Through recognising these tendencies, teacher researchers began to challenge their own preconceptions and to appreciate the significant benefits of alternative teaching approaches for these students: "I tried a few things with my bottom set and their 
motivation has just been so high in those particular lessons that I've had to very rarely like tell them to get on with things or to do things" (Anna, Interview 3). They began to question their prior assumptions about mathematical ability. Reviewing setting was not an explicit focus for the research project, since the teacher researchers were not in positions to influence policy on grouping students within their schools. Despite this, they voiced growing criticism of setting and increasingly questioned its validity and benefits, thus challenging discourses around ability on which setting is predicated (Francis et al. 2017): 'I'd like to bring in Year 7's, unsetted [mixed attainment groups], at some point, once I'd gained my school's trust. This is if I even get a head of department job, but that's the long-term goal" (Anna, Interview 2).

Another significant shift in thinking amongst teacher researchers was from viewing education as a meritocracy towards recognising structural causes of inequity. All five had chosen an ITE programme that deliberately placed them in schools in relatively deprived areas of London, on the premise that inequalities in educational outcomes can be addressed by focusing on raising the attainment of disadvantaged students:

I've chosen to teach in a school where it's classed as a challenging school, because the kids stereotypically wouldn't be expected to achieve very much. ... So I think, in the sense of bringing about social justice through education, I'm involved in that just through being at this school. (Anna, Interview 1).

In accepting this discourse, equity-oriented teachers are compelled to work as hard as possible to enable some students from poorer backgrounds to achieve higher grades and hence realise higher aspirations, e.g. in gaining access to more prestigious universities. Bourdieu and Passeron (1990) argue that every such success merely gives credibility to the myth that the school system represents a true meritocracy. Engaging with research literature, and relating this to their own practice, encouraged teacher researchers to question previous assumptions: "People say 'Well, we've got a good education system, you know, we live in a country where you can get wherever you want'. Well actually, people can't, because of the barriers" (Anna, Interview 2). Brian began to articulate how, in order to be successful in mathematics, all students need to develop the personal and social skills necessary to take advantage of opportunities to learn. This resonates with Jorgensen's (2016) contention that teachers should strive to enable working-class children to realign their values and behaviours with those recognised by the school.

Whilst observing the benefits of alternative pedagogies employed through the research project, the teacher researchers became increasingly aware of the constraints they faced in developing these pedagogies, through their schools' excessive focus on high-stakes examination and monitoring of teachers. They described how the tendency of managers to carry out brief unannounced visits to classrooms (often referred to as learning walks) resulted in pressure to make it appear as though students are working hard and making progress at all times:

I think it makes you less likely to take risks with your classes. If you know that there's a chance that someone pops in, you're more likely to do lots of very average lessons, than one lesson that could blow up in your face or it could go amazingly, because you know that you'd be judged on that one lesson. (Brian, Interview 1)

This might help to explain the prevalence of transmissionist teaching approaches, given the pressures on teachers to demonstrate students' short-term gains in attainment rather than focusing on longer-term improvements in students' dispositions towards learning mathematics (Williams and Choudhury 2016). 
The teacher researchers observed that some higher-attaining students showed the least enthusiasm for alternative teaching approaches, perhaps reflecting that they felt comfortable with the status quo and the personal success they associated with it:

I think, if you are at the top end of the top set, you've put your hat on the fact that you get things right, and as soon as in maths it's no longer about you getting the right numerical answer, you suddenly feel like things are not under your control any more, and you're not top dog any more. (Brian, Interview 2).

Boaler (2009) highlights, however, how success is not necessarily accompanied by positive dispositions towards learning mathematics, with many high-attaining students failing to see its relevance to their future lives and choosing not to study mathematics beyond the compulsory stage. Thus, assigning greater emphasis to the use value of mathematics means that all students, not just the low-attaining, have something to gain.

One of the most interesting findings was that, despite its limited scale, the project generated a substantial amount of interest from other teachers not directly involved. The teacher researchers described how news of the positive impact of the activities on their students' engagement and achievement spread quickly across their departments causing a rapid growth in interest from colleagues. George described this as the multiplier effect: "Success has bred more success, because if they've seen a lesson go well, then they want to teach it, and then their lesson goes well, and then it sort of spreads" (Rebecca, Interview 3). In response to demands for more information, all five teacher researchers disseminated ideas to colleagues who were keen to try these out themselves. Anna, Brian and Rebecca were invited to run training sessions for their departments and three schools adopted activities from the project for use with a whole year group. This suggests the existence of a wider group of teachers receptive to the aims of the research project beyond those volunteering themselves as teacher researchers.

\section{How can PAR bring about transformations in classroom practice?}

The findings of the TMSJ project presented in the previous section demonstrate how one research project, which adopted the critical research model of PAR, brought about significant changes in teacher researchers' thinking and classroom practice and provided their students with a more engaging and empowering mathematical learning experience. In this section, I draw on the second thematic analysis (referred to earlier) to examine how the above was achieved through the application of the critical research model (Skovsmose and Borba 2004). I highlight the characteristics of PAR, in particular the three key processes and strategies for ensuring reliability (described earlier), that demonstrate its potential for bringing about transformations in classroom practice in a context in which more conventional approaches to research have had limited impact.

\section{Pedagogical imagination}

The TMSJ project was participatory in the sense that the teacher researchers played a leading role in deciding how the conceptualisation of teaching mathematics for social justice (described earlier) should be translated into practice through activities and teaching approaches to be tried out and implemented in the classroom. My role in the research group was largely facilitative, i.e. organising and publicising meetings, inviting suggestions 
for the agendas and chairing discussions, summarising and clarifying decisions taken by the group, writing up and circulating notes from the meetings. The teacher researchers acknowledged the pivotal role that I played in encouraging them to engage with theoretical ideas and research literature, which I selected as relevant to the aims of the project, by presenting papers to each other for discussion. This reinforced the importance of external stimulus in promoting critical reflection whilst conducting collaborative enquiry (Jaworski 2006). At the same time, teacher researchers appreciated the opportunities to take decisions themselves relating to the research design and articulated a growing interest in, and understanding of, research processes: "This is my only experience of any kind of research ... I have learnt an awful lot about the process, as opposed to just what we're researching" (Rebecca, Meeting 4).

Whilst the adoption of this pre-existing conceptualisation might be seen as contradicting the participatory principles of PAR (by deciding in advance the focus for the research), it was effective in promoting critical reflection, with teacher researchers describing how it helped them to recognise existing practice as problematic by relating it to the research literature (Hatton and Smith 1995; Liu 2015). This illustrates a careful balance that needs to be established within PAR between the academic researcher acting as an external stimulus, promoting a critical understanding of current practice, and the agency of teacher researchers in playing an integral role in the design and development of the research project.

\section{Practical organisation}

The teacher researchers emphasised how the mutual support provided by the group enabled them to overcome constraints and gave them the confidence to take risks in developing their own practice. A striking example of this was the way in which the group rallied around Rebecca when she became disheartened by frustrations she experienced during early trials of the Making a Change project: "It is quite useful having that kind of, I don't know, support almost and being able to just tell someone exactly what happened and have their, kind of, outside view on it" (Rebecca, Interview 2). The reassurance, encouragement and constructive feedback she received led to her (and others) recognising the potential benefits of the activity, which subsequently became the main focus for the third action research cycle. Holding regular group meetings (seven over the course of one year) also provided the impetus required to maintain the momentum of the project:

And it's also provided that additional incentive to do it, and to take the risk, because you know that you're going to be asked to talk about it. But also you know you're going to be allowed to talk about it in a way that says that messing up doesn't matter. (Brian, Interview 3).

The teacher researchers took much of the initiative for organising the action research cycles, choosing which activities to try out in the classroom and evaluating the success of these activities during research group meetings.

\section{Explorative reasoning}

The project highlighted the importance of establishing a genuinely collaborative approach between academic researcher and teacher researchers. This necessitated the teacher researchers and I recognising and respecting each other's expertise and appreciating how each other's contributions strengthen the robustness of the research design (Atweh 2004). 
The existence of such a collaborative relationship was apparent in the discussions accompanying the development of the student surveys. My familiarity with research methods enabled me to present options for how feedback might be collected from students, whilst the teacher researchers' detailed knowledge of the classroom context informed the joint decision taken to employ student surveys. Similarly, the formulating of questions and the development of a protocol for administering the surveys drew heavily on the range of expertise available within the research group.

The five teacher researchers were drawn from four different schools. They welcomed the opportunity to discuss ideas, share experiences and to collaboratively plan a series of activities with teachers from outside their own schools, highlighting how this exposed them to a wider range of perspectives and allowed them to be more open in evaluating their own teaching:

Through sharing resources when we all have a clear focus, and we've all agreed on what we're trying to achieve, you cut through all the rubbish, really. And the discussions give you fresh ideas you might not have thought about. (Anna, Interview 3).

\section{Reliability of research findings}

Potential problems with the credibility of the findings were considered by the research group and strategies agreed to mitigate against these. The possibility of bias arising in the student surveys, due to students' responses being influenced by what they believed teachers wanted to hear, was minimised by emphasising to students (through the survey protocol) the anonymity of the survey and that the results would be used solely for the purpose of the research project. A similar bias was possible in the data generated from research group meetings and interviews which were based primarily on teacher researchers self-reporting on their perceptions of students' engagement and achievement. However, the responses from the student surveys and the final reports written by teacher researchers appeared to resonate closely with the initial findings from the thematic analyses. The responses from the teacher researchers when reviewing these findings suggested they considered these to accurately represent the accounts given during meetings and interviews. Indeed, George described how hearing the findings presented back helped him to make more sense of the story he had narrated. This suggests that the strategies described above along with others described earlier (including prolonged engagement and iterative questioning) ensured the credibility of the findings.

What has emerged clearly from these findings is the crucial role of the academic researcher within PAR in ensuring confirmability, i.e. that the research findings are derived from teacher researchers' experiences. Reflexivity appears to be vital for the academic researcher in making effective use of her/his research knowledge and expertise to inform decision making, whilst facilitating teacher researchers' agency in conducting the research. One way in which this was achieved in the TMSJ project was through me introducing Skovsmose and Borba's (2004) critical research model of PAR and Lincoln and Guba's (2003) framework for ensuring trustworthiness, and prompting discussions around how these could be used by the group to inform the research design and to conduct the research in a systematic and rigorous way. This requires a high degree of transparency in sharing, and encouraging teacher researchers to engage with, the methodology underlying the research.

It should be acknowledged that there were aspects of the research for which I took more direct responsibility, e.g. collecting and analysing data (from the research group meetings and interviews) and disseminating the findings from the TMSJ project. Whilst the method 
for analysing data was discussed at length in research group meetings, given the time constraints on teacher researchers, it was me that carried out the coding. I also took responsibility for conducting the interviews. Given the participatory nature of the research group meetings and the empathetic approach to interviewing, which both generated the data, I consider this to be in line with the principles of PAR. However, given the extent to which teacher researchers engaged with the research processes, involving them more in conducting interviews and coding data is something I would be keen to explore in future studies. Another aspect that might be explored in greater depth is the extent to which teacher researchers are able to develop and maintain changes in practice beyond the duration of the project and how these relate to the organisational constraints they encounter in schools (which is beyond the scope of the TMSJ project).

It is important that all researchers should learn from their involvement in PAR. Whilst the project demonstrated how teacher researchers benefited through developing a deeper understanding of theory in practice (Brydon-Miller et al. 2003), conducting this analysis has also enabled me to progress my own understanding of how theory relating to PAR relates to my own professional context as a teacher educator and academic researcher. This paper is an attempt to share the insight I have gained from the project into how PAR can be conducted in a way that promotes critical reflection and transforms classroom practice.

\section{Conclusion}

Conventional approaches to teaching, based on transmissionist pedagogies and adhering to an exercise paradigm (Skovsmose 2011), are well established in mathematics classrooms. They have proved resistant to change for many years, protected by powerful discourses that present inequities in school and society as inevitable. Mathematics education research, which too often fails to take account of the sociopolitical nature of school mathematics and constraints teachers face in the classroom, has had limited success in challenging these pedagogies and effecting changes in practice. Some pockets of innovative practice exist which challenge these discourses; however, the challenge for those seeking change is formidable.

Research that aims to challenge social inequity through transforming classroom practice must take account of the structural causes of inequity as well as the constraints faced by teachers who wish to develop more empowering pedagogies. Participatory action research (PAR), in which teachers and researchers work collaboratively in order to challenge the current situation, offers a methodology that has the potential to achieve both of these objectives. It satisfies commonly accepted criteria for the effective professional learning of mathematics teachers (Geiger et al. 2016), i.e. it involves engagement over a long period, is carried out within teachers' own working environments and involves teachers reflecting critically on their practice. By exploring new pedagogies within the context of teacher researchers' own classrooms, it can generate findings that are more relevant and applicable to other classroom situations and that take account of the constraints teachers face.

The Teaching Mathematics for Social Justice (TMSJ) research project demonstrated how teachers can challenge dominant pedagogical discourses in order to develop alternative teaching approaches that engage a wider range of students, whilst enhancing their mathematical agency and enabling them to develop powerful forms of mathematics knowledge. By reflecting on how a critical model of PAR was applied in the design of the TMSJ project, I have demonstrated how PAR can be conducted in a systematic and rigorous way 
in order to generate reliable and trustworthy findings. I have shown how teacher researchers can play a leading role in the design of classroom trials and in the development of research tools to evaluate their success. I have highlighted how the input from an academic researcher can provide the external stimulus necessary for teachers to challenge orthodox thinking through engaging with theories and research literature that advocate an alternative vision of mathematics education. Conversely, the active participation of teachers in the research process can provide an academic researcher with greater insight into the classroom context in which the research is situated. I have demonstrated how a group of mathematics teachers from a number of different schools can work together with an academic researcher to develop a critical understanding of their own situation and provide the mutual support necessary to identify and overcome the constraints they face in transforming their practice.

The project highlighted the existence of a wider group of teachers in schools, who are potentially interested in adopting more empowering approaches to teaching mathematics, but who may only be persuaded to devote time for trying these out once they have seen the positive outcomes achieved in colleagues' classrooms. My experience as a teacher educator is that many teachers decide to join the profession out of a concern for issues of equity and social justice, but then lose sight of this aspiration once they become assimilated into its prevailing practices and discourses. This group of teachers might therefore be bigger than many people think. The substantial interest shown in the project by other teachers not initially involved underlines the potential of the critical research model of PAR to have a wider impact on classroom practice in a formal school setting through a bottom-up approach that involves collaborations between teachers and academics. It is the responsibility of critical mathematics educators, of whom I consider myself to be one of many, to initiate and facilitate such opportunities, to provide the external stimulus necessary for critical reflection to occur, and to develop models of PAR that enable such transformations in classroom practice to take place.

Open Access This article is licensed under a Creative Commons Attribution 4.0 International License, which permits use, sharing, adaptation, distribution and reproduction in any medium or format, as long as you give appropriate credit to the original author(s) and the source, provide a link to the Creative Commons licence, and indicate if changes were made. The images or other third party material in this article are included in the article's Creative Commons licence, unless indicated otherwise in a credit line to the material. If material is not included in the article's Creative Commons licence and your intended use is not permitted by statutory regulation or exceeds the permitted use, you will need to obtain permission directly from the copyright holder. To view a copy of this licence, visit http://creativecommons.org/licenses/by/4.0/.

\section{References}

ACME. (2011). Mathematical needs-summary. London: Advisory Committee on Mathematics Education.

Andersson, A., \& Valero, P. (2016). Negotiating critical pedagogical discourses: Stories of contexts, mathematics, and agency. In P. Ernest \& B. Sriraman (Eds.), Critical mathematics education: Theory, praxis, and reality (pp. 199-226). Charlotte, NC: Information Age.

Atweh, B. (2004). Understanding for change and changing for understanding: Praxis between practice and theory through action research in mathematics education. In P. Valero \& R. Zevenbergen (Eds.), Researching the socio-political dimensions of mathematics education (pp. 187-205). Dordrecht: Kluwer.

Barrett, B. (2017). Bernstein in the urban classroom: A case study. British Journal of Sociology of Education. https://doi.org/10.1080/01425692.2016.1269632. 
BERA. (2017). Tender: Dimensions of quality in close-to-practice educational research. Retrieved March 17, 2017, from https://www.bera.ac.uk/opportunity/tender-dimensions-of-quality-in-close-to-practiceeducational-research.

Bishop, A. J. (1998). Research, effectiveness, and the practitioners' world. In A. Sierpinska \& J. Kilpatrick (Eds.), Mathematics education as a research domain: A search for identity (pp. 33-45). Dordrecht: Kluwer.

Black, L., Mendick, H., \& Solomon, Y. (2009). Mathematical relationships in education: Identities and participation. New York, NY: Routledge.

Boaler, J. (2008). Promoting 'relational equity' and high mathematics achievement through an innovative mixed-ability approach. British Educational Research Journal, 34(2), 167-194.

Boaler, J. (2009). The elephant in the classroom: Helping children learn and love maths. London: Souvenir Press.

Boaler, J., Altendorf, L., \& Kent, G. (2011). Mathematics and science inequalities in the United Kingdom: When elitism, sexism and culture collide. Oxford Review of Education, 37(4), 457-484.

Bourdieu, P., \& Passeron, J.-C. (1990). Reproduction in education, society and culture (2nd ed.). London: Sage.

Brydon-Miller, M., Greenwood, D., \& Maguire, P. (2003). Why action research? Action Research, 1(1), 9-28.

Brydon-Miller, M., \& Maguire, P. (2009). Participatory action research: Contributions to the development of practitioner inquiry in education. Educational Action Research, 16(1), 79-93.

Cockcroft, W. H. (1982). Mathematics counts: Report of the Committee of Inquiry into the Teaching of Mathematics in Schools under the chairmanship of W.H. Cockcroft. London: Her Majesty's Stationery Office.

Cordingley, P. (2013). The contribution of research to teachers' professional learning and development. London: Research and teacher education: The BERA-RSA Inquiry.

Cotton, T. (2013). Critical mathematics education: From theory to practice. In A. Coles, R. Barwell, T. Cotton, J. Winter, \& L. Brown (Eds.), Teaching secondary mathematics as if the planet matters (pp. 87-97). Abingdon: Routledge.

D’Ambrosio, B., Frankenstein, M., Gutiérrez, R., Kastberg, S., Bernard Martin, D., Moschkovich, J., et al. (2013). Introduction to the JRME Equity special issue. Journal for Research in Mathematics Education, 44(1), 5-10.

DFE. (2013). Mathematics programmes of study: Key stage 3. London: Department for Education.

DFEE. (2001). Key Stage 3 National Numeracy Strategy: Framework for teaching mathematics: Years 7, 8 and 9. London: Department for Education and Employment.

Duncan-Andrade, J., \& Morrell, E. (2008). The art of critical pedagogy: Possibilities for moving from theory to practice in urban schools. New York, NY: Peter Lang.

Ernest, P. (2016). The scope and limits of critical mathematics education. In P. Ernest, B. Sriraman, \& N. Ernest (Eds.), Critical mathematics education: Theory, practice and reality (pp. 99-126). Charlotte, NC: Information Age Publishing.

Ernest, P., \& Sriraman, B. (2016). Foreword. In P. Ernest, B. Sriraman, \& N. Ernest (Eds.), Critical mathematics education: Theory, practice and reality (pp. vii-xi). Charlotte, NC: Information Age Publishing.

Fontana, A., \& Frey, J. H. (2008). The interview: From neutral stance to political involvement. In N. K. Denzin \& Y. S. Lincoln (Eds.), Collecting and interpreting qualitative materials (pp. 115-159). London: SAGE.

Foster, C. (2013). Resisting reductionism in mathematics pedagogy. The Curriculum Journal, 24(4), 565-585.

Francis, B., Archer, L., Hodgen, J., Pepper, D., Taylor, B., \& Travers, M.-C. (2017). Exploring the relative lack of impact of research on 'ability grouping' in England: A discourse analytic account. Cambridge Journal of Education, 47(1), 1-17.

Gates, P., \& Jorgensen, R. (2009). Foregrounding social justice in mathematics teacher education. Journal of Mathematics Teacher Education, 12(3), 161-170.

Geiger, V., Muir, T., \& Lamb, J. (2016). Video-stimulated recall as a catalyst for teacher professional learning. Journal of Mathematics Teacher Education, 19, 457-475.

Gibson, W. J., \& Brown, A. (2009). Working with qualitative data. London: Sage.

Gough, D. (2004). Systematic research synthesis. In G. Thomas \& R. Pring (Eds.), Evidence-based practice in education (pp. 44-62). Maidenhead: Open University Press.

Grootenboer, P. (2013). The praxis of mathematics teaching: Developing mathematical identities. Pedagogy, Culture and Society, 21(2), 321-342.

Gutstein, E. (2006). Reading and writing the world with mathematics: Toward a pedagogy for social justice. New York, NY: Routledge. 
Gutstein, E., \& Peterson, B. (2005). Rethinking mathematics: Teaching social justice by the numbers. Milwaukee, WI: Rethinking Schools Ltd.

Hammersley, M. (2004). Some questions about evidence-based practice in education. In G. Thomas \& R. Pring (Eds.), Evidence-based practice in education (pp. 133-149). Maidenhead: Open University Press.

Hatton, N., \& Smith, D. (1995). Reflection in teacher education: Towards definition and implementation. Teaching and Teacher Education, 11(1), 33-49.

Hodgen, J., \& Marks, R. (2009). Mathematical 'ability' and identity: A sociocultural perspective on assessment and selection. In L. Black, H. Mendick, \& S. Solomon (Eds.), Mathematical relationships in education: Identities and participation (pp. 31-42). New York, NY: Routledge.

Jackson, A. Y., \& Mazzei, L. A. (2012). Thinking with theory in qualitative research: Viewing data across multiple perspectives. Abingdon: Routledge.

Jaworski, B. (2006). Theory and practice in mathematics teaching development: Critical inquiry as a mode of learning in teaching. Journal of Mathematics Teacher Education, 9(2), 187-211.

Jorgensen, R. (2016). The elephant in the room: Equity, social class, and mathematics. In P. Ernest, B. Sriraman, \& N. Ernest (Eds.), Critical mathematics education: Theory, practice and reality (pp. 127-146). Charlotte, NC: Information Age Publishing.

Jorgensen, R., Gates, P., \& Roper, V. (2014). Structural exclusion through school mathematics: Using Bourdieu to understand mathematics as a social practice. Educational Studies in Mathematics, 87, 221-239.

Kemmis, S. (2009). Action research as a practice-based practice. Educational Action Research, 17(3), 463-474.

Kvale, S., \& Brinkmann, S. (2009). Interviews: Learning the craft of qualitative research interviewing. London: Sage Publications.

Leat, D., Lofthouse, R., \& Reid, A. (2014). Teachers' views: Perspectives on research engagement. London: Research and Teacher Education: The BERA-RSA Inquiry.

Lincoln, Y. S., \& Guba, E. G. (2003). Paradigmatic controversies, contradictions, and emerging confluences. In N. K. Denzin \& Y. S. Lincoln (Eds.), The landscape of qualitative research: Theories and issues (pp. 253-291). Thousand Oaks, CA: Sage.

Liu, K. (2015). Critical reflection as a framework for transformative learning in teacher education. Educational Review, 67(2), 135-157.

Morgan, C. (2010). Making sense of curriculum innovation and mathematics teacher identity. In C. Kanes (Ed.), Elaborating professionalism: Studies in practice and theory (pp. 107-122). Dordrecht: Springer.

Myhill, D. (2015). A self-improving system. Research Intelligence, 126, 20-21.

Nardi, E., \& Steward, S. (2003). Is mathematics T.I.R.E.D.? A profile of quiet disaffection in the secondary mathematics classroom. British Educational Research Journal, 29(3), 345-367.

NCETM. (2008). Mathematics matters-final report. London: National Centre for Excellence in Teaching Mathematics.

Norton, S. (2017). Mathematics engagement in an Australian lower secondary school. Journal of Curriculum Studies, 49(2), 169-190.

Noyes, A. (2008). Mathematical marginalisation and meritocracy: Inequity in an English classroom. In B. Sriraman (Ed.), International perspectives on social justice in mathematics education (pp. 51-68). Charlotte, NC: Information Age Publishing.

Noyes, A. (2009). Exploring social patterns of participation in university-entrance level mathematics in England. Research in Mathematics Education, 11(2), 167-183.

Oakley, A. (2006). Resistances to 'new' technologies of evaluation: Education research in the UK as a case study. Evidence and Policy, 2(1), 63-87.

Oates, T. (2010). Could do better: Using international comparisons to refine the National Curriculum in England. Cambridge: Cambridge Assessment.

OFSTED. (2012). Mathematics: Made to measure. Manchester: The Office for Standards in Education, Children's Services and Skills.

QCA. (2007). The National Curriculum for England at Key Stages 3 and 4. London: Qualifications and Curriculum Authority.

Raygoza, M. C. (2016). Striving toward transformational resistance: Youth participatory action research in the mathematics classroom. Journal of Urban Mathematics Education, 9(2), 122-152.

Robutti, O., Cusi, A., Clark-Wilson, A., Jaworski, B., Chapman, O., Esteley, C., et al. (2016). ICME international survey on teachers working and learning through collaboration: June 2016. ZDM Mathematics Education, 48(5), 651-690. 
Sebba, J. (2004). Developing evidence-informed policy and practice in education. In G. Thomas \& R. Pring (Eds.), Evidence-based practice in education (pp. 34-43). Maidenhead: Open University Press.

Shenton, A. K. (2004). Strategies for ensuring trustworthiness in qualitative research projects. Education for Information, 22, 63-75.

Skemp, R. (1972). The psychology of learning mathematics. London: Penguin.

Skovsmose, O. (2011). An invitation to critical mathematics education. Rotterdam: Sense Publishers.

Skovsmose, O., \& Borba, M. (2004). Research methodology and critical mathematics education. In P. Valero \& R. Zevenbergen (Eds.), Researching the socio-political dimensions of mathematics education (pp. 207-226). Dordrecht: Kluwer Academic Publishers.

Smith, A. (2004). Making mathematics count: The report of Professor Adrian Smith's inquiry into post14 mathematics education. London: The Stationery Office Ltd.

Straehler-Pohl, H., \& Gellert, U. (2013). Towards a Bernsteinian language of description for mathematics classroom discourse. British Journal of Sociology of Education, 34(3), 313-332.

Strutchens, M., Bay-Williams, J., Civil, M., Chval, K., Malloy, C., White, D., et al. (2012). Foregrounding equity in mathematics teacher education. Journal of Mathematics Teacher Education, 15, 1-7.

Swan, M. (2006). Collaborative learning in mathematics: A challenge to our beliefs and practices. Leicester: National Institute of Adult Continuing Education.

Takahashi, A., \& McDougal, T. (2016). Collaborative lesson research: Maximizing the impact of lesson study. ZDM Mathematics Education, 48, 513-526.

Thiollent, M. (2011). Action research and participatory research: An overview. International Journal of Action Research, 7(2), 160-174.

Thomas, G. (2004). Introduction: Evidence and practice. In G. Thomas \& R. Pring (Eds.), Evidence-based practice in education (pp. 1-18). Maidenhead: Open University Press.

Valero, P. (2004). Socio-political perspectives on mathematics education. In P. Valero \& R. Zevenbergen (Eds.), Researching the socio-political dimensions of mathematics education (pp. 5-23). Dordrecht: Kluwer Academic Publishers.

Vorderman, C. (2011). A world-class mathematics education for all our young people. London: Conservative Party.

Wake, G., Swan, M., \& Foster, C. (2016). Professional learning through the collaborative design of problem-solving lessons. Journal of Mathematics Teacher Education, 19, 243-260.

Watson, A., Jones, K., \& Pratt, D. (2013). Key ideas in teaching mathematics: Research-based guidance for ages 9-19. Oxford: Oxford University Press.

Wilkinson, S., \& Penney, D. (2014). The effects of setting on classroom teaching and student learning in mainstream mathematics, English and science lessons: A critical review of the research literature in England. Educational Review, 66(4), 411-427.

Williams, J., \& Choudhury, S. (2016). Mathematics capital in the educational field: Beyond Bourdieu. Research in Mathematics Education, 18(1), 3-21.

Winch, C., Oancea, A., \& Orchard, J. (2013). The contribution of educational research to teachers' professional learning-philosophical understandings. London: Research and Teacher Education: The BERA-RSA Inquiry.

Wright, P. (2004). Human Rights in the Curriculum: Mathematics. London: Amnesty International UK.

Wright, P. (2015). Teaching mathematics for social justice: Translating theories into practice. Ed.D. dissertation, University of Sussex (Sussex Research Online).

Wright, P. (2016). Social justice in the mathematics classroom. London Review of Education, 14(2), $104-118$.

Wright, P. (2017). Critical relationships between teachers and learners of school mathematics. Pedagogy, Culture and Society, 25(4), 515-530.

Yasukawa, K., Skovsmose, O., \& Ravn, O. (2016). Scripting the world in mathematics and its ethical implications. In P. Ernest, B. Sriraman, \& N. Ernest (Eds.), Critical mathematics education: Theory, practice and reality (pp. 81-98). Charlotte, NC: Information Age Publishing.

Publisher's Note Springer Nature remains neutral with regard to jurisdictional claims in published maps and institutional affiliations. 